\title{
Improved performance in master runners competing in the European Championships between 1978 and 2014
}

\author{
Schneider, Anaïs L ; Nikolaidis, Pantelis Theodoros ; Knechtle, Beat
}

\begin{abstract}
The performance trends in elite runners have been well investigated, but we have no knowledge about performance trends and the difference between the sexes in elderly runners competing at a high level in varying distances. The purpose of this study was to investigate the performance of these age groups. Data from seventeen European Championships held between 1978 and 2014 were analyzed for various race distances (i.e. $100 \mathrm{~m}, 200$ $\mathrm{m}, 400 \mathrm{~m}, 800 \mathrm{~m}, 1500 \mathrm{~m}, 5000 \mathrm{~m}, 10,000 \mathrm{~m}$ and marathon). Running speed for the top 8 female and male finalists for each age group (35-99 years, split into 5 year gaps) and each race distance were included. A two-way analysis of variance compared the effects of sex, race distance, age group and calendar year on speed. Subsequent comparisons between race distances, age groups or calendar years were carried out using a post-hoc Bonferroni test. Our analysis shows that men were faster than women in all distances and the difference between the sexes was greater in the shorter distances. Speed was higher for shorter distances than for longer distances. Younger participants were faster than older ones, and the effect of age group was the largest for the $200 \mathrm{~m}$. There was a minor effect of calendar year on speed in the $100 \mathrm{~m}, 200 \mathrm{~m}, 1500 \mathrm{~m}, 10,000 \mathrm{~m}$ and marathon, and a minor calendar year $\times$ sex interaction on running speed was shown for the $200 \mathrm{~m}$. For athletes and coaches, the current study demonstrates that both male and female athletes improved their running performance over time and that the sex gap may have reached its limit.
\end{abstract}

DOI: https://doi.org/10.1519/JSC.0000000000002548

Posted at the Zurich Open Repository and Archive, University of Zurich

ZORA URL: https://doi.org/10.5167/uzh-152639

Journal Article

Accepted Version

Originally published at:

Schneider, Anaïs L; Nikolaidis, Pantelis Theodoros; Knechtle, Beat (2019). Improved performance in master runners competing in the European Championships between 1978 and 2014. Journal of Strength and Conditioning Research, 33(9):2559-2569.

DOI: https://doi.org/10.1519/JSC.0000000000002548 
Improved Performance in Master Runners Competing in the European

Championships between 1978 and 2014

Performance trends in master runners grouped by age

\author{
Anaïs L. Schneider ${ }^{1}$, Pantelis T. Nikolaidis ${ }^{2}$, Beat Knechtle ${ }^{1,3}$ \\ ${ }^{1}$ Institute of Primary Care, University of Zurich, Zurich, Switzerland \\ ${ }^{2}$ Exercise Physiology Laboratory, Nikaia, Greece \\ ${ }^{3}$ Medbase St. Gallen Am Vadianplatz, St. Gallen, Switzerland
}

Corresponding author:

Prof. Dr. med. Beat Knechtle

Facharzt FMH für Allgemeinmedizin

Medbase St. Gallen Am Vadianplatz

Vadianstrasse 26

9001 St. Gallen

Switzerland

Telefon $\quad+41(0) 712269300$

Telefax $\quad+41(0) 712269301$

E-Mail beat.knechtle@hispeed.ch 


\section{Abstract}

2 The performance trends in elite runners have been well investigated, but we have no

3 knowledge about performance trends and the difference between the sexes in elderly

4 runners competing at a high level in varying distances. The purpose of this study was

5 to investigate the performance of these age groups. Data from seventeen European

6 Championships held between 1978 and 2014 were analyzed for various race distances

7 (i.e. $100 \mathrm{~m}, 200 \mathrm{~m}, 400 \mathrm{~m}, 800 \mathrm{~m}, 1500 \mathrm{~m}, 5000 \mathrm{~m}, 10,000 \mathrm{~m}$ and marathon).

8 Running speed for the top 8 female and male finalists for each age group (35-99

9 years, split into 5 year gaps) and each race distance were included. A two-way

10 analysis of variance compared the effects of sex, race distance, age group and

11 calendar year on speed. Subsequent comparisons between race distances, age groups

12 or calendar years were carried out using a post-hoc Bonferroni test. Our analysis

13 shows that men were faster than women in all distances and the difference between

14 the sexes was greater in the shorter distances. Speed was higher for shorter distances

15 than for longer distances. Younger participants were faster than older ones, and the

16 effect of age group was the largest for the $200 \mathrm{~m}$. There was a minor effect of

17 calendar year on speed in the $100 \mathrm{~m}, 200 \mathrm{~m}, 1500 \mathrm{~m}, 10,000 \mathrm{~m}$ and marathon, and a

18 minor calendar yearxsex interaction on running speed was shown for the $200 \mathrm{~m}$. For

19 athletes and coaches, the current study demonstrates that both male and female

20 athletes improved their running performance over time and that the sex gap may have

21 reached its limit.

23 Key words: speed; runner; sex difference; age group athlete 


\section{INTRODUCTION}

25 Track and road running is an increasingly popular sports discipline, where participants

26 aim to cover a given distance - usually from $100 \mathrm{~m}$ to marathon - as fast as possible

27 (62). The last few years have seen an increase in participation, especially in marathon

28 road running $(21,37)$. Despite the growing participation in running events of varying

29 distances, little is known about the performance trends of elderly female and male

30 elite athletes in track running (49).

31 Running speed has improved considerably for both women and men during the last

32150 years (62). World records in all running events have been continually beaten over

33 the past century (41). Several factors might contribute to the dramatic increase in running performance. In the late 1970s sports physiology began to be applied to sports training strategies. Different training methods were incorporated, including circuit training, interval training and sprints. A better understanding of various training components probably played a major role in the increase of performance in the last decades (59). Incorporation of an interyal training session has been proven to increase running speed on longer runs and lengthen the time to exhaustion in trained athletes (32). During the last century, studies started to include research about resistance training. The first studies about resistance training started in the 1980s. Since then it has been shown that resistance training has an impact on neural mechanisms, metabolic adaptations, the cardiovascular system, the endocrine system, connective tissue and the immune system (33). Changes in training strategies such as an increased training volume helped achieve this progress (52). A greater interest in sport psychology might have helped understanding an athlete's psychological needs in order to perform better (34). Keegan et al. studied the impact of coaches, parents and peers on an athlete's motivation and showed that the behaviour of the people in an 
49 athlete's environment has a direct, but complex impact on his or her motivation (25).

50 Coaching strategies have changed over time and provide athletes with better

51 techniques for coping with anxiety, which can negatively affect athletic performance 52 (44).

53 Progress in the medical field might also play a role as it provides more concise

54 medical advice in terms of prevention and therapy of sport injuries (59). For example, 55 research about overtraining syndrome in athletes helps understand the aetiology of 56 this condition and how to avoid and treat it (6). Radiographic imaging, arthroscopy 57 and new surgical methods help provide a better, more complete medical support and 58 play a major role in the increase of performance (59). Another contributing factor 59 might be found in the better understanding of the nutritional demands of an athlete's 60 body (59) and of the hydration needed during endurance performance (26). Advances

61 in health technology including the development of functional magnetic resonance 62 imaging have helped understand brain activity during sports (19).

63 In the last decades, considerable advances have also been made in the field of sports

64 equipment. We now have access to improved design and quality of shoes, clothing 65 and training equipment. These improvements also helped athletes achieve an increase 66 in sports performance (59). Unfortunately, doping probably also plays a major role in 67 the increase of athletic performance in the last few decades (41). All of these factors and more could play a role in the overall increase of athletic performance.

69 Men run faster than women. There are several reasons for this difference in endurance 70 performance between the sexes, including higher $\mathrm{VO}_{2} \max$, lower body fat percentage 71 (55), larger hearts, higher haemoglobin levels and greater muscle mass in men (4).

72 Endocrine differences are not to be neglected. Androgens levels are higher in men, 
and contribute to their higher muscle mass (51), which has an impact on neuromuscular performance (12). Although both men and women have improved their running performance, the relative improvement in running performance observed over the last century was greater in female than in male athletes (41). Some findings even suggested that women would outrun men at some point in the future $(64,65)$.

The hypothesis of the narrowing difference between the sexes in running performance has been analysed by other authors $(8,21,54,68)$. For instance, Zingg et al. (69) showed that female athletes over 35 years reduced the difference in mountain and city marathons within a decade. In 1922, the difference was about $30 \%$ and decreased over time, reaching a plateau at $10.7 \%$ in 1984 , according to Thibault et al. (58). Other authors state a similar percentage $(15,21)$. Interestingly, one study shows that the difference between the sexes is smaller in ultra-marathon running, ranging from 0.2$10 \%$ (31). The discussion of whether women will catch up to men or whether the difference might be fixed is still ongoing.

Elderly athletes represent a highly active and healthy population with a good quality of life (67). Thus, studies of performance of this athletic elderly population might help to understand the decline in general health with increasing age (67). Aging is generally associated with a decline in both health $(40,67)$ and endurance performance (56). Over the last few decades, however, greater numbers of elderly people have participated in endurance races $(23,42,56)$. In running, elderly athletes have significantly improved their performance between 1975 and 2013 (2).

Regular endurance training, including running, has many health benefits. Several studies demonstrated the benefits of physical activity later in life such as lower overall mortality $(18,63)$ Lee et al. analysed the mortality risk of over 13,000 runners and 
97 found out that runners have a lower mortality risk than non-runners (36). It has been

98 shown that regular exercise reduces the incidence of cardiovascular and respiratory

99 diseases (46). Couppé et al. found that elderly men who had been practicing

100 endurance running for a long time had lower triglyceride and LDL-cholesterol than

101 untrained elderly men. The same group analysed accumulation of advanced glycation

102 end products in the connective tissue and showed that elderly elite athletes have a

103 lower AGE accumulation and higher MRI signal intensity of the patellar tendon,

104 suggesting that endurance training could reduce the age-related deterioration of soft

105 tissues (11). Regular physical exercise has also been shown to improve cognitive

106 function (57).

107 Based on existing reports describing other disciplines like swimming (27) where

108 improvement over time was shown for elderly swimmers in all age groups and

109 distances, we might assume similar trends in running; however, we have no

110 knowledge about changes in performance trends in age group track runners competing

111 at an elite level in various distances. Such knowledge would be of great value from a

112 theoretical and practical perspective. Sports scientists, especially exercise

113 physiologists, focusing on sex differences would benefit from such knowledge,

114 because they would improve their understanding of the evolution of the differences

115 between males and females in sport performance. On the other hand, coaches and

116 fitness trainers working with age group runners might use such information on sex

117 differences to optimize the training of their athletes.

118 The possibility of a sub-2-hour marathon has been discussed vividly lately. Though

119 runners are getting faster over time, Tucker et al. do not believe in an imminent sub 2-

120 hour marathon because the current average difference between the sexes is about

$121 \quad 11.2 \%$ and the achievement of a sub 2-hour marathon would represent a $12.9 \%$ 
122 difference. Another point they bring forward is that the $2.4 \%$ required improvement in

123 men's performance is unlikely to happen quickly, but rather will take generations to

124 achieve (60). Hoogkamer et al. do believe a sub 2-hour marathon is achievable and

125 drew a draft of how a lighter shoe, a downhill route and tailwind might someday

126 reduce the metabolic cost enough in order to achieve the average velocity of $5.86 \mathrm{~m} / \mathrm{s}$

127 required for a sub 2-hour marathon (20).

128 The first aim of this study was to analyse the performance trends in elite master

129 runners from 1978 until 2014 for 5-year age group intervals from 35 to 99 years for

130 different race distances (i.e. 100 m, 200 m, 400 m, 800 m, 1500 m, 5000 m, 10,000 m

131 and marathon). The second aim was to analyse the difference between men's and

132 women's running performance. We hypothesized that between 1978 and 2014 both

133 men and women improved their running speed and that the difference between the

134 sexes decreased.

136 METHODS

\section{Experimental Approach to the Problem}

138 In order to investigate the changes of performance (i.e. running speed) of master

139 athletes across the years along with the difference in performance between men and

140 women, we analysed the running speed of men and women for different distances.

141 Data from 17 European Championships held between 1978 and 2014 were analyzed

142 for different race distances (i.e. 100 m, 200 m, 400 m, 800 m, 1500 m, 5000 m,

$14310,000 \mathrm{~m}$ and marathon). Only outdoor track races and marathons held on roads were

144 included due to the different events (e.g. $100 \mathrm{~m}$ versus $60 \mathrm{~m}$ ) and conditions (e.g. 400

$145 \mathrm{~m}$ in one lap versus $400 \mathrm{~m}$ in two laps) in outdoor and indoor races, respectively. The 
146 youngest athletes in the data set were 35 years old. Reaburn and Dascombe (49)

147 defined master athletes as participants of 35 years or older. We therefore considered

148 athletes over 35 years of age to be master athletes and did not include any younger

149 athletes in our study.

150 Subjects

151 The European Veterans Athletic Association (EVAA) was founded in 1978 in Italy

152 with the aim to organize European Championships for master athletes and to keep a

153 complete register of the results (http://european-masters-athletics.org/about-

154 us/history.html). We aimed to investigate the results of the European Championships

155 held between 1978 and 2014. The section www.evaa.ch/results.html records the

156 publicly available race results for the years 2000-2014. The result charts for races held

157 between 1978 and 2000 were not available on the website, thus, Ove Edlund, Sweden,

158 provided us with the printed versions for this time period. Both the online and the

159 printed race records included results for the distances $100 \mathrm{~m}, 200 \mathrm{~m}, 400 \mathrm{~m}, 800 \mathrm{~m}$,

$1601500 \mathrm{~m}, 5000 \mathrm{~m}, 10,000 \mathrm{~m}$ and the marathon. Each athlete was recorded for distance,

161 race time, nationality and age group. Not every Championships result chart included

162 the competitor's exact age, however, every Championships used the same age groups

163 where athletes were divided into 5-year age group intervals as follows: 35-39, 40-44,

$16445-49,50-54,55-59,60-64,65-69,70-74,75-79,80-84,85-89,90-94$, and 95-99

165 years. To our knowledge no subject was excluded from the EVAA data set because of

166 the use of doping. This study was approved by the Institutional Review Board of

167 Kanton St. Gallen, Switzerland, with a waiver of the requirement for informed

168 consent of the participants as the study involved the analysis of publicly available data

$169(01 / 06 / 2010)$. 
170

171 We analysed the running performance for athletes between 35 and 99 in 5-year age

\section{Procedures} intervals. The race distances included were $100 \mathrm{~m}, 200 \mathrm{~m}, 400 \mathrm{~m}, 800 \mathrm{~m}, 1500 \mathrm{~m}$, $5000 \mathrm{~m}, 10,000 \mathrm{~m}$ and marathon. Finally, 14,685 race times $(6,019$ female and 8,666

male times) were included into the data set. The data set is visible in Table 1. For better comparison, we restricted our analysis to the top eight male and female finishers, as there were different numbers of finishers in each category. Finishers without a recorded race time or who were disqualified for any reason were excluded from our analysis. Running speed was used to compare the performance. As the race times and the distances but not the running speed were listed in the result charts, running speed was calculated in $\mathrm{km} / \mathrm{h}$ using the equation running speed $(\mathrm{km} / \mathrm{h})=$ race distance $(\mathrm{m}) /$ race time $(\mathrm{sec}) \times 3.6$.

\section{Statistical Analyses}

\section{The statistical software IBM SPSS v.23.0 (SPSS, Chicago, USA) performed all} statistical analyses. Mean values and standard deviation (s) were calculated for all variables. A two-way analysis of variance (ANOVA) compared effects of sex, race distance, age group and calendar year on running speed. Subsequent comparisons among race distances, age groups and calendar years were carried out using post-hoc Bonferroni test. The magnitude of these differences was examined using effect size eta squared $\left(\eta^{2}\right)$ and evaluated as: minor $\left(0.010<\eta^{2} \leq 0.059\right)$, moderate $\left(0.059<\eta^{2} \leq 0.138\right)$ and major $\left(\eta^{2}>0.138\right)(9)$. We analysed the relationship between speed and race duration using a logarithmic regression model. In addition, we examined the differences in the running speed of men and women using the formula 
$194100 \times($ men's running speed-women's running speed)/women's running speed. We

195 also compared variations in running speed by participants' sex, age group, race

196 distance and calendar year by a mixed-effects regression model. In this model,

197 participants were assigned as random variables, whereas sex, age group, race distance

198 and calendar year were assigned as fixed variables. We examined interaction effects

199 among these fixed variables. Akaike information criterion (AIC) was used to select

200 the final model. These analyses were performed for each race distance separately. A

201 regression analysis of cubic degree was performed between running speed and

202 calendar year, and the coefficient of determination $\left(\mathrm{R}^{2}\right)$ was calculated. Statistical

203 significance was set at alpha $=0.05$.

\section{RESULTS}

\section{Performance by sex and race distance}

207 According to the two-way ANOVA, a moderate effect of sex on running speed was

208 observed $\left(\mathrm{p}<0.001, \eta^{2}=0.115\right)$, where men were faster than women, as shown in

209 Figure 1. Also, a major effect of race distance on running speed was shown $(\mathrm{p}<$

$\left.2100.001, \eta^{2}=0.649\right)$, where short distances were faster than longer ones. In addition, a

211 sex $\times$ race distance interaction on running speed was noticed $\left(p<0.001, \eta^{2}=0.006\right)$ for

212 all distances with the sex difference being greater in the shorter distances. These

213 findings were in agreement with the mixed-effects regression analysis and are shown

214 in Table 2. Figure 2 presents the relationship between running speed and race

215 duration. 
218 A major effect of sex on running speed $(\mathrm{p}<0.001)$, where men were faster than

219 women, was observed for all distances with $\eta^{2}$ ranging from $0.197(1000 \mathrm{~m})$ to 0.472

220 (200 m). Figure 3 represents the difference between the sexes for each distance and

221 each age group. In addition, a major effect of age group on running speed $(\mathrm{p}<0.001)$,

222 where the younger groups were faster than the older, was shown for all distances with

$223 \eta^{2}$ ranging from 0.474 (marathon) to $0.823(200 \mathrm{~m})$. A minor sex $\times$ age group

224 interaction on running speed $(\mathrm{p}<0.001)$, where difference between the sexes was

225 greater in the younger age groups, was noticed for all distances with $\eta^{2}$ ranging from

$2260.019(1500 \mathrm{~m})$ to $0.048(100 \mathrm{~m})$. The findings of the mixed-effects regression

227 analysis were shown in Table 3.

Performance by sex between 1978 and 2014

230 A minor effect of calendar year on running speed was observed in 100 m, $200 \mathrm{~m}$,

$2311500 \mathrm{~m}, 10,000 \mathrm{~m}$ and marathon $\left(\mathrm{p} \leq 0.044,0.014 \leq \eta^{2} \leq 0.050\right)$, but not in $400 \mathrm{~m}$,

$232800 \mathrm{~m}$ and $5000 \mathrm{~m}\left(\mathrm{p} \geq 0.160, \eta^{2} \leq 0.011\right)$ (Figure 4). A small calendar year $\times$ sex

233 interaction on running speed $\left(\mathrm{p}=0.038, \eta^{2}=0.013\right)$ was shown for $200 \mathrm{~m}$, but not for

234 the rest of the distances. The findings of the mixed-effects regression analysis were

235 presented in Table 3. The regression analysis of cubic degree between sex difference

236 and calendar year showed variation by race distance: $100 \mathrm{~m}\left(\mathrm{R}^{2}=0.41\right), 200 \mathrm{~m}\left(\mathrm{R}^{2}=\right.$

$2370.34), 400 \mathrm{~m}\left(\mathrm{R}^{2}=0.628\right), 800 \mathrm{~m}\left(\mathrm{R}^{2}=0.309\right), 1500 \mathrm{~m}\left(\mathrm{R}^{2}=0.209\right), 5000 \mathrm{~m}\left(\mathrm{R}^{2}=\right.$

$2380.328), 10,000 \mathrm{~m}\left(\mathrm{R}^{2}=0.489\right)$ and marathon $\left(\mathrm{R}^{2}=0.046\right)$. These findings are shown

239 in Table 4 and Figure 5. 


\section{DISCUSSION}

242 The main findings of the present study were that (i) men were faster than women in

243 all distances, (ii) the difference between men and women in running speed was greater

244 in the shorter distances, with the greatest difference in $200 \mathrm{~m}$ and the smallest in

$24510,000 \mathrm{~m}$, (iii) running speed was faster for shorter distances than for longer

246 distances, (iv) younger participants were faster than older ones, (v) with the effect of

247 age group the largest in $200 \mathrm{~m}$ and the smallest for the marathon, (vi) there was a

248 minor effect of calendar year on running speed in $100 \mathrm{~m}, 200 \mathrm{~m}, 1500 \mathrm{~m}, 10,000 \mathrm{~m}$

249 and marathon, and (vii) a minor calendar year×sex interaction in running speed was

250 shown for $200 \mathrm{~m}$.

251

252 Men were faster than women for all distances and age groups

253 The first result was that men were faster than women for all distances and age groups,

254 which was supported by other studies $(21,54)$. Generally speaking, the difference of

255 10-12\% between male and female running speeds has been consistent for both shorter

256 and longer distances (16).

257 Although one might argue that this result was trivial, recent studies investigating

258 master pool swimmers in freestyle (27), breaststroke (29), backstroke (61) and open-

259 water swimmers (28) showed that men were faster than women for younger age

260 groups, but not for older age groups where women achieved a similar performance to

261 men. The explanation was that in the studies with swimmers at the World

262 Championships, no selection by age group occurred and all swimmers in all age

263 groups were considered. The men-to-women ratio changed across age groups and, 
264 therefore, explains the fact that women were able to achieve a similar performance to men in the older age groups.

266 Men were faster than women in our study. This may be due to their lower body fat

267 percentage and their higher $\mathrm{VO}_{2} \max (55)$ compared to women. However, these

268 hypotheses were limited, as we did not perform any determinations of body fat or

$269 \mathrm{VO}_{2} \max$. Men also seem to be more competitive (13) and more willing to commit to a 270 high intensity training program (16) than women. There might also be a historical

271 component as it is known that women have been participating in official races for a

272 shorter period of time and have therefore less experience in running races (21). We

273 did not collect any historical data ourselves, but it is known that the first modern

274 Olympic Games were introduced in 1896 with only male athletes, and a century later

275 (in 1984), female runners were first included for the marathon distance (59).

276 There are other differences between male and female runners. Women tend to have a

277 more even pace throughout a race, while men slow down for the second half of the

278 marathon (14). This difference might be due to different choices while racing or to the

279 fact that men are depleting their muscle glycogen more rapidly than women (14).

280 In the present study we used running as a way to compare male and female

281 performance and the changes over time. Distance running is a suitable discipline to

282 compare male and female performance because it is objective, open to everyone who

283 wants to participate and popular among men and women (13). Sex differences in

284 endurance performance were also found in other athletic disciplines. In swimming

285 races, the sex differences seem more important in elderly than in younger swimmers,

286 though not as important as in marathon running (53). 
289

290

291

A second important discovery was that the difference in male and female running speed was greater for shorter distances and smaller for longer distances. The effect of sex was the highest for the $200 \mathrm{~m}$ distance and the smallest for the $10,000 \mathrm{~m}$ distance. Sprint performance depends on peak power output, which increases linearly with the amount of lean mass in the lower extremities, and is higher in males (43).

Proportionally, women oxidize more fat than men during endurance exercise (7),

which might help explain why women are less fatigued on longer distances (8). Other contributing factors to fatigue could be hormonal differences as oestrogens are known to have a protective role in exercise-related muscle damage that accompanies longer aerobic exercise (66).

\section{Running speed was faster for shorter distances}

Another discovery was that running speed was faster for shorter distances than for longer ones. This result was expected and has been demonstrated by other authors. For example, Weiss et al. (62) showed that running speed decreased with increasing race distance. Different physiological factors cause a reduction of physical effort including cardiorespiratory capacity, $\mathrm{VO}_{2}$ max and muscle fatigue (24).

\section{Younger athletes were faster than elderly athletes}

Another important result was that younger competitors ran faster than elderly athletes for every distance. This effect of age on running speed was expected and has been demonstrated by other authors $(10,21,30,56)$. 
311 The best running times are often achieved by the age of 35 years with a small and

312 linear decline until about 50-60 years of age, with a more pronounced decline after

313 that (56). A decline in $\mathrm{VO}_{2}$ which is due to a reduction in cardiac output, an increase

314 in body fat percentage, a reduction in peripheral oxygen extraction and most

315 importantly, a reduction in muscle mass (48), seems to play an important role in the

316 decline of running performance in elderly athletes (47). Younger master athletes have

317 higher muscle mass and a greater number of motor units than older master athletes

318 (17). Muscle atrophy causes a reduction of muscle mass $(1,3)$. Muscle atrophy in turn

319 could partially be explained by neuronal dysfunction (5). Therefore, the age-related

320 muscle loss contributes to the reduction of $\mathrm{VO}_{2} \max (48)$ which in turn plays an

321 important role in the age-related decrease of running speed (47).

322 The oldest competitors in our study were 97 years old, but other authors reported great 323 sports performance of centenarians (38), showing that physical activity is possible

324 until late in life. Age-related sarcopenia could also play a role in the performance 325 decline. Sarcopenia is defined by a decrease in number and function of muscle fibres.

326 It is the result of yarious factors including age-related defect in autophagy resulting in

327 protein accumulation, impaired mitochondrial function due to increased reactive

328 oxygen species, diminished regenerative potential of muscle fibres, degenerative

329 atrophy, vitamin deficiencies and hormonal changes. Muscle mass and strength are

330 also linked to testosterone levels. An increase in age correlates to decreased

331 testosterone levels in both men and women, which is linked to a decrease in muscle

332 mass, particularly in men (45) 
336 Another finding was that the age-associated decline in performance was the largest for

337 the $200 \mathrm{~m}$ distance and the smallest for the marathon. There are divergent results in

338 current literature. Rittweger et al. showed that the age-related decrease in running

339 performance was similar for both sprint and long-distance runners (50). Drey et al.

340 (17) compared the skeletal muscle mass in power- and endurance-trained master

341 athletes competing in the 2012 European Championship held in Zittau, Germany.

342 Power-trained master athletes had a better muscle mass than endurance-trained master

343 athletes (17). During the aging process relatively more type II muscle fibres are lost

344 (39). This could explain why in our study, the age-related decline was more

345 pronounced for the $200 \mathrm{~m}$ distance and smallest for the marathon. Both sprinting and

346 long-distance training are beneficial during the aging process (35). The fact that 99-

347 year old athletes were competing in Championships shows that aging might come

348 with a decrease in running performance but it is compatible with an active lifestyle.

Effect of calendar year on speed in $100 \mathrm{~m}, 200 \mathrm{~m}, 1500 \mathrm{~m}, 10,000 \mathrm{~m}$ and

marathon

352 Another important discovery was an effect of calendar year on running speed for most

353 distances. It has been suggested by different authors that running performance has

354 been improving over the years $(56,62)$. World records in athletic sports like running

355 have dramatically increased over the past century. The improvements in race times

356 were directly proportional to race distances, meaning the smallest improvements were

357 achieved on short distances like $100 \mathrm{~m}$ and the largest improvements were observed in 
358 longer distances such as marathon running (41). Weiss et al. showed that the

359 improvement observed at the beginning of the century is now stagnating (62).

\section{Small calendar year×sex interaction on speed for $\mathbf{2 0 0} \mathbf{~ m}$}

361 The last significant finding was that the difference between the sexes has decreased

362 over the years, but only for the $200 \mathrm{~m}$ distance. We expected that the difference would

363 be decreasing for every distance; however, results of earlier studies were divergent.

364 Thibault et al. (58) showed that the difference has been stable since 1984 and that the

365 gap will most likely not be closed. Hunter et al. (22) show that the difference

366 diminished between 1980 and 2010. The researchers also claimed that the male-

367 female difference is closely linked to the male-female participation ratio and therefore

368 many studies have a historical and sampling bias (21).

\section{Limitations and strengths}

371 A limitation of these discoveries was that the present study focused on European

372 athletes and outdoor Championships. Thus, caution was needed to generalize these

373 findings to non-European athletes and indoor Championships. Non-Europeans showed

374 superior performance in athletic running events and their performance would be

375 expected to vary differently by calendar year and sex. Moreover, some events differed

376 between outdoor and indoor competitions (e.g. $100 \mathrm{~m}$ versus $60 \mathrm{~m}, 5000 \mathrm{~m}$ versus

$3773000 \mathrm{~m}$, respectively) or do not exist in indoors competitions (10,000 $\mathrm{m}$ and marathon)

378 and those which existed in both competitions (e.g. $400 \mathrm{~m}$ ) included different numbers

379 of laps (e.g. one versus two) affecting the physiological, technical and tactical

380 demands of a similar distance. Nevertheless, the strength of the study was its novelty 
381 as it is the first one in this topic, adding novel information about the variation of

382 performance of master runners by calendar year and sex.

384 In conclusion, male runners are generally faster than females. The the gap between

385 male and female endurance performance has been decreasing over the past decades

386 but that it seems to have reached a limit. In general, all athletes are getting faster over 387 time.

\section{PRACTICAL APPLICATIONS}

390 For athletes and coaches, information acquired through this study could have practical

391 implications for practitioners working with master runners; most training programs

392 were developed and applied originally in men, and, thus, knowledge about sex

393 differences would help coaches designing tailored training programs for women, as

394 well. In addition to this practical application, the results about the variation of

395 performance by age group and the variation of the effect of age by race distance

396 would be of interest for researchers studying master athletes as a model of effective

397 aging and for sports scientists, especially exercise physiologists, focusing on sex

398 differences in sport performance.

\section{Acknowledgements}

401 We thank Ove Edlund, Sweden, for providing us the data before the year 2000 and

402 Mrs Knechtle for transcribing this data set. We also thank Patricia Villiger for her

403 help in translation. 


\section{References}

1. Akima H, Kano Y, Enomoto Y, Ishizu M, Okada M, Oishi Y, Katsuta S, and Kuno S. Muscle function in 164 men and women aged 20--84 yr. Med Sci Sports Exerc 33: 220-226, 2001.

2. Akkari A, Machin D, and Tanaka H. Greater progression of athletic performance in older Masters athletes. Age and Ageing 44: 683-686, 2015.

3. Brooks SV and Faulkner JA. Skeletal muscle weakness in old age: underlying mechanisms. Med Sci Sports Exerc 26: 432-439, 1994.

4. Brown N and Scurr J. Do women with smaller breasts perform better in longdistance running? European journal of sport science 16: 965-971, 2016.

5. Campbell MJ, McComas AJ, and Petito F. Physiological changes in ageing muscles. J Neurol Neurosurg Psychiatry 36: 174-182, 1973.

6. Carfagno DG and Hendrix JC, 3rd. Overtraining syndrome in the athlete: current clinical practice. Current sports medicine reports 13: 45-51, 2014.

7. Carter SL, Rennie C, and Tarnopolsky MA. Substrate utilization during endurance exercise in men and women after endurance training. Am J Physiol Endocrinol Metab 280: E898-907, 2001.

8. Coast JR, Blevins JS, and Wilson BA. Do gender differences in running performance disappear with distance? Can J Appl Physiol 29: 139-145, 2004.

9. Cohen J. Statistical power analysis for the behavioral sciences. Hillsdale, NJ: Lawrence Erlbaum Associates, 1988.

10. Connick MJ, Beckman EM, and Tweedy SM. Relative age affects marathon performance in male and female athletes. Journal of Sports Science and Medicine 14: 669-674, 2015.

11. Couppe C, Svensson RB, Grosset JF, Kovanen V, Nielsen RH, Olsen MR, Larsen JO, Praet SF, Skovgaard D, Hansen M, Aagaard P, Kjaer M, and Magnusson SP. Life-long endurance running is associated with reduced glycation and mechanical stress in connective tissue. Age (Dordrecht, Netherlands) 36: 9665, 2014.

12. Crewther BT, Cook C, Cardinale M, Weatherby RP, and Lowe T. Two emerging concepts for elite athletes: the short-term effects of testosterone and cortisol on the neuromuscular system and the dose-response training role of these endogenous hormones. Sports medicine (Auckland, NZ) 41: 103-123, 2011.

13. Deaner RO. Distance running as an ideal domain for showing a sex difference in competitiveness. Archives of Sexual Behavior 42: 413-428, 2013.

14. Deaner RO, Addona V, Carter RE, Joyner MJ, and Hunter SK. Fast men slow more than fast women in a 10 kilometer road race. PeerJ 2016, 2016.

15. Deaner RO and Mitchell D. More men run relatively fast in U.S. road races, 1981-2006: a stable sex difference in non-elite runners. Evol Psychol 9: 600$621,2011$.

16. Deaner RO and Mitchell D. More men run relatively fast in U.S. road races, 1981-2006: a stable sex difference in non-elite runners. Evolutionary psychology : an international journal of evolutionary approaches to psychology and behavior 9: 600-621, 2011.

17. Drey M, Sieber CC, Degens H, McPhee J, Korhonen MT, Müller K, Ganse B, and Rittweger J. Relation between muscle mass, motor units and type of 
training in master athletes. Clinical Physiology and Functional Imaging 36:

70-76, 2016.

18. Ekelund U, Steene-Johannessen J, Brown WJ, Fagerland MW, Owen N, Powell KE, Bauman A, and Lee IM. Does physical activity attenuate, or even eliminate, the detrimental association of sitting time with mortality? A harmonised meta-analysis of data from more than 1 million men and women. Lancet, 2016.

19. Holmes PS and Wright DJ. Motor cognition and neuroscience in sport psychology. Current opinion in psychology 16: 43-47, 2017.

20. Hoogkamer W, Kram R, and Arellano CJ. How Biomechanical Improvements in Running Economy Could Break the 2-hour Marathon Barrier. Sports medicine (Auckland, NZ), 2017.

21. Hunter SK and Stevens AA. Sex differences in marathon running with advanced age: physiology or participation? Med Sci Sports Exerc 45: 148-156, 2013.

22. Hunter SK, Stevens AA, Magennis K, Skelton KW, and Fauth M. Is there a sex difference in the age of elite marathon runners? Med Sci Sports Exerc 43: 656-664, 2011.

23. Jokl P, Sethi PM, and Cooper AJ. Master's performance in the New York City Marathon 1983-1999. Br J Sports Med 38: 408-412, 2004.

24. Kayser B. Exercise starts and ends in the brain. European Journal of Applied Physiology 90: 411-419, 2003.

25. Keegan R, Harwood C, Spray C, and Lavallee D. A qualitative investigation of the motivational climate in elite sport. Psychology of Sport and ExerciseElsevier Ltd 2013, pp 97-107.

26. Kenefick RW and Cheuvront SN. Hydration for recreational sport and physical activity. Nutr Rev 70 Supp1 2: S137-142, 2012.

27. Knechtle B, Nikolaidis PT, König S, Rosemann T, and Rüst CA. Performance trends in master freestyle swimmers aged 25-89 years at the FINA World Championships from 1986 to 2014. Age 38: 1-8, 2016.

28. Knechtle B, Nikolaidis PT, Rosemann T, and Rüst CA. Performance trends in $3000 \mathrm{~m}$ open-water age group swimmers from 25 to 89 years competing in the FINA World Championships from 1992 to 2014. Research in Sports Medicine 25: 67-77, 2017.

29. Knechtle B, Nikolaidis PT, Rosemann T, and Rust CA. Performance trends in age group breaststroke swimmers in the FINA World Championships 19862014. The Chinese journal of physiology 59: 247-259, 2016.

30. Knechtle B, Rust CA, Rosemann T, and Lepers R. Age-related changes in 100-km ultra-marathon running performance. Age (Dordrecht, Netherlands) 34: 1033-1045, 2012.

31. Knechtle B, Valeri F, Nikolaidis P, Zingg M, Rosemann T, and Rüst C. Do women reduce the gap to men in ultra-marathon running? 2016.

32. Koral J, Oranchuk DJ, Herrera R, and Millet GY. Six Sessions of Sprint Interval Training improves running performance in trained athletes. Journal of strength and conditioning research, 2017.

33. Kraemer WJ, Ratamess NA, Flanagan SD, Shurley JP, Todd JS, and Todd TC. Understanding the Science of Resistance Training: An Evolutionary Perspective. Sports medicine (Auckland, NZ), 2017. 
34. Kremer J and Moran A. Swifter, higher, stronger: The history of sport psychology. The psychologist, 2008, pp 740-742.

35. Kusy K and Zieliński J. Sprinters versus long-distance runners: How to grow old healthy. Exercise and Sport Sciences Reviews 43: 57-64, 2015.

36. Lee DC, Pate RR, Lavie CJ, Sui X, Church TS, and Blair SN. Leisure-time running reduces all-cause and cardiovascular mortality risk. Journal of the American College of Cardiology 64: 472-481, 2014.

37. Lepers $\mathrm{R}$ and Cattagni $\mathrm{T}$. Do older athletes reach limits in their performance during marathon running? 2011.

38. Lepers R, Stapley PJ, and Cattagni T. Centenarian athletes: Examples of ultimate human performance? Age and Ageing 45: 729-733, 2016.

39. Lexell J. Human aging, muscle mass, and fiber type composition. Journals of Gerontology - Series A Biological Sciences and Medical Sciences 50: 11-16, 1995.

40. Leyk D, Erley O, Ridder D, Leurs M, Ruther T, Wunderlich M, Sievert A, Baum K, and Essfeld D. Age-related changes in marathon and half-marathon performances. Int J Sports Med 28: 513-517, 2007.

41. Lippi G, Banfi G, Favaloro EJ, Rittweger J, and Maffulli N. Updates on improvement of human athletic performance: focus on world records in athletics. Br Med Bull 87: 7-15, 2008.

42. Mohlenkamp S, Lehmann N, Breuckmann F, Brocker-Preuss M, Nassenstein K, Halle M, Budde T, Mann K, Barkhausen J, Heusch G, Jockel KH, and Erbel R. Running: the risk of coronary events : Prevalence and prognostic relevance of coronary atherosclerosis in marathon runners. Eur Heart J 29: 1903-1910, 2008.

43. Moon JR. Role of muscle mass on sprint performance: Gender differences? by Jorge Perez-Gomez, German Vicente Rodriguez, Ignacio Ara, Hugo Olmedillas, Javier Chavarren, Juan Jose González-Henriquez, Cecilia Dorado and José A. L. Calbet. European Journal of Applied Physiology 103: 375, 2008.

44. Mottaghi M, Atarodi A, and Rohani Z. The Relationship between Coaches' and Athletes' Competitive Anxiety,and their Performance. Iran J Psychiatry Behav Sci 7: 68-76, 2013.

45. Naranjo JD, Dziki JL, and Badylak SF. Regenerative Medicine Approaches for Age-Related Muscle Loss and Sarcopenia: A Mini-Review. Gerontology 63: 580-589, 2017.

46. Paffenbarger RS, Jr., Hyde RT, Wing AL, and Hsieh CC. Physical activity, all-cause mortality, and longevity of college alumni. N Engl J Med 314: 605613, 1986.

47. Pollock ML, Foster C, Knapp D, Rod JL, and Schmidt DH. Effect of age and training on aerobic capacity and body composition of master athletes. Journal of Applied Physiology 62: 725-731, 1987.

48. Proctor DN and Joyner MJ. Skeletal muscle mass and the reduction of VO2max in trained older subjects. Journal of Applied Physiology 82: 14111415, 1997.

49. Reaburn P and Dascombe B. Anaerobic performance in masters athletes. European Review of Aging and Physical Activity 6: 39-53, 2009.

50. Rittweger J, Di Prampero PE, Maffulli N, and Narici MV. Sprint and endurance power and ageing: An analysis of master athletic world records. Proceedings of the Royal Society B: Biological Sciences 276: 683-689, 2009. 
51. Rossetti ML, Steiner JL, and Gordon BS. Androgen-mediated regulation of skeletal muscle protein balance. Molecular and cellular endocrinology 447: 35-44, 2017.

52. Salinero JJ, Soriano ML, Lara B, Gallo-Salazar C, Areces F, Ruiz-Vicente D, Abian-Vicen J, Gonzalez-Millan C, and Del Coso J. Predicting race time in male amateur marathon runners. J Sports Med Phys Fitness, 2016.

53. Senefeld J, Joyner MJ, Stevens A, and Hunter SK. Sex differences in elite swimming with advanced age are less than marathon running. Scand J Med Sci Sports 26: 17-28, 2016.

54. Senefeld J, Smith C, and Hunter SK. Sex Differences in Participation, Performance, and Age of Ultramarathon Runners. International journal of sports physiology and performance 11: 635-642, 2016.

55. Sparling PB and Cureton KJ. Biological determinants of the sex difference in 12-min run performance. Medicine and Science in Sports and Exercise 15: 218-223, 1983.

56. Tanaka H and Seals DR. Endurance exercise performance in Masters athletes: age-associated changes and underlying physiological mechanisms. J Physiol 586: 55-63, 2008.

57. Tarumi T, Gonzales MM, Fallow B, Nualnim N, Lee J, Pyron M, Tanaka H, and Haley AP. Cerebral/Peripheral Vascular Reactivity and Neurocognition in Middle-Age Athletes. Med Sci Sports Exerc 47: 2595-2603, 2015.

58. Thibault V, Guillaume M, Berthelot G, Helou NE, Schaal K, Quinquis L, Nassif H, Tafflet M, Escolano S, Hermine O, and Toussaint JF. Women and Men in Sport Performance: The Gender Gap has not Evolved since 1983. J Sports Sci Med 9: 214-223, 2010.

59. Tipton CM. Sports medicine: a century of progress. J Nutr 127: 878s-885s, 1997.

60. Tucker R and Santos-Concejero J. "An Imminent Sub 2-Hours Marathon is Unlikely: historical Trends of the Gender Gap in Running Events". International journal of sports physiology and performance: 1-18, 2016.

61. Unterweger CM, Knechtle B, Nikolaidis PT, Rosemann T, and Rust CA. Increased participation and improved performance in age group backstroke master swimmers from 25-29 to 100-104 years at the FINA World Masters Championships from 1986 to 2014. Springerplus 5: 645, 2016.

62. Weiss M, Newman A, Whitmore C, and Weiss S. One hundred and fifty years of sprint and distance running - Past trends and future prospects. European journal of sport science 16: 393-401, 2016.

63. Wen CP, Wai JP, Tsai MK, Yang YC, Cheng TY, Lee MC, Chan HT, Tsao $\mathrm{CK}$, Tsai SP, and $\mathrm{Wu} \mathrm{X}$. Minimum amount of physical activity for reduced mortality and extended life expectancy: a prospective cohort study. Lancet 378: 1244-1253, 2011.

64. Whipp BJ and Ward SA. Will women soon outrun men? Nature 355: 25, 1992.

65. Whyte G. Age, sex and (the) race: gender and geriatrics in the ultra-endurance age. Extrem Physiol Med 3: 1, 2014.

66. Williams T, Walz E, Lane AR, Pebole M, and Hackney AC. The effect of estrogen on muscle damage biomarkers following prolonged aerobic exercise in eumenorrheic women. Biol Sport 32: 193-198, 2015.

67. Wright VJ and Perricelli BC. Age-related rates of decline in performance among elite senior athletes. Am J Sports Med 36: 443-450, 2008. 
68. Zingg MA, Karner-Rezek K, Rosemann T, Knechtle B, Lepers R, and Rust CA. Will women outrun men in ultra-marathon road races from $50 \mathrm{~km}$ to 1,000 km? Springerplus 3: 97, 2014.

602

69. Zingg MA, Knechtle B, Rust CA, Rosemann T, and Lepers R. Reduced

603 performance difference between sexes in master mountain and city marathon running. International journal of general medicine 6: 267-275, 2013.

604 
Table 1 Available data for each race distance at the events considered in our study

\begin{tabular}{|c|c|c|c|c|c|c|c|c|c|c|}
\hline & & & $100 \mathrm{~m}$ & $200 \mathrm{~m}$ & $400 \mathrm{~m}$ & $800 \mathrm{~m}$ & $1500 \mathrm{~m}$ & $5000 \mathrm{~m}$ & $1000 \mathrm{~m}$ & marathon \\
\hline \multirow[t]{2}{*}{1978} & Viareggio & men & $\mathrm{X}$ & $\mathrm{X}$ & $\mathrm{x}$ & $\mathrm{X}$ & $\mathrm{x}$ & $\mathrm{X}$ & $\mathrm{x}$ & $\mathrm{x}$ \\
\hline & & women & & & & & $\mathrm{x}$ & $\mathrm{X}$ & & $\mathrm{x}$ \\
\hline \multirow[t]{2}{*}{1980} & Helsinki & men & $\mathrm{X}$ & $\mathrm{X}$ & $\mathrm{x}$ & $\mathrm{X}$ & $\mathrm{x}$ & $\mathrm{X}$ & $\mathrm{x}$ & $\mathrm{x}$ \\
\hline & & women & $\mathrm{X}$ & $\mathrm{X}$ & $\mathrm{X}$ & $\mathrm{x}$ & $\mathrm{x}$ & $\mathrm{X}$ & & $\mathrm{X}$ \\
\hline \multirow[t]{2}{*}{1982} & Strasbourg & men & $\mathrm{X}$ & $\mathrm{x}$ & $\mathrm{x}$ & $\mathrm{x}$ & $\mathrm{x}$ & & X & $\mathrm{x}$ \\
\hline & & women & $\mathrm{X}$ & $\mathrm{X}$ & $\mathrm{x}$ & $\mathrm{x}$ & $\mathrm{x}$ & & $\mathrm{X}$ & $\mathrm{x}$ \\
\hline \multirow[t]{2}{*}{1984} & Brighton & men & $\mathrm{x}$ & $\mathrm{x}$ & $\mathrm{x}$ & $\mathrm{x}$ & & & & \\
\hline & & women & $\mathrm{X}$ & $\mathrm{x}$ & $\mathrm{x}$ & $\mathrm{x}$ & & X & & \\
\hline \multirow[t]{2}{*}{1986} & Malmö & men & $\mathrm{x}$ & $\mathrm{x}$ & $\mathrm{x}$ & $\mathrm{X}$ & & $\mathrm{x}$ & $\mathrm{x}$ & $\mathrm{x}$ \\
\hline & & women & $\mathrm{X}$ & $\mathrm{x}$ & $\mathrm{x}$ & $\mathrm{X}$ & & & $\mathrm{x}$ & $\mathrm{X}$ \\
\hline \multirow[t]{2}{*}{1990} & Budapest & men & $\mathrm{X}$ & $\mathrm{x}$ & $\mathrm{X}$ & $\mathrm{x}$ & $\mathrm{x}$ & $\mathrm{x}$ & $\mathrm{x}$ & \\
\hline & & women & & & & & & & & \\
\hline \multirow[t]{2}{*}{1994} & Athen & men & $\mathrm{x}$ & $\mathrm{X}$ & $\mathrm{x}$ & $\mathrm{x}$ & $\mathrm{x}$ & $\mathrm{x}$ & $\mathrm{x}$ & $\mathrm{x}$ \\
\hline & & women & $\mathrm{X}$ & & X & $\mathrm{x}$ & $\mathrm{x}$ & $\mathrm{x}$ & $\mathrm{x}$ & $\mathrm{X}$ \\
\hline \multirow[t]{2}{*}{1996} & Malmö & men & $\mathrm{x}$ & $\mathrm{X}$ & $\mathrm{x}$ & $\mathrm{x}$ & $\mathrm{x}$ & $\mathrm{x}$ & $\mathrm{x}$ & $\mathrm{x}$ \\
\hline & & women & & & $\mathrm{X}$ & $\mathrm{x}$ & $\mathrm{x}$ & $\mathrm{x}$ & $\mathrm{x}$ & $\mathrm{x}$ \\
\hline \multirow[t]{2}{*}{1998} & Cesenatico & men & $\mathrm{X}$ & $\mathrm{x}$ & $\mathrm{x}$ & $\mathrm{x}$ & $\mathrm{x}$ & $\mathrm{x}$ & $\mathrm{X}$ & $\mathrm{x}$ \\
\hline & & women & $\mathrm{x}$ & & $\mathrm{X}$ & $\mathrm{X}$ & $\mathrm{x}$ & $\mathrm{x}$ & $\mathrm{x}$ & $\mathrm{X}$ \\
\hline \multirow[t]{2}{*}{2000} & Jyväskylä & men & $\mathrm{x}$ & $\mathrm{X}$ & $\mathrm{x}$ & $\mathrm{X}$ & $\mathrm{x}$ & $\mathrm{x}$ & $\mathrm{x}$ & $\mathrm{X}$ \\
\hline & & & & $\mathrm{x}$ & $\mathrm{X}$ & $\mathrm{X}$ & $\mathrm{X}$ & $\mathrm{x}$ & $\mathrm{X}$ & $\mathrm{X}$ \\
\hline \multirow[t]{2}{*}{2002} & Potsdam & men & $\mathrm{x}$ & $\mathrm{X}$ & $\mathrm{x}$ & $\mathrm{x}$ & $\mathrm{x}$ & $\mathrm{x}$ & $\mathrm{x}$ & \\
\hline & & women & $\mathrm{x}$ & $\mathrm{X}$ & $\mathrm{X}$ & $\mathrm{x}$ & $\mathrm{x}$ & $\mathrm{x}$ & $\mathrm{x}$ & \\
\hline \multirow[t]{2}{*}{2004} & Aarhus & men & $\mathrm{x}$ & $\mathrm{X}$ & $\mathrm{x}$ & $\mathrm{x}$ & $\mathrm{x}$ & $\mathrm{x}$ & $\mathrm{x}$ & $\mathrm{x}$ \\
\hline & & women & $\mathrm{x}$ & $\mathrm{X}$ & $\mathrm{x}$ & $\mathrm{x}$ & $\mathrm{x}$ & $\mathrm{x}$ & $\mathrm{X}$ & $\mathrm{x}$ \\
\hline \multirow[t]{2}{*}{2006} & Poznan & men & $\mathrm{X}$ & $\mathrm{X}$ & $\mathrm{x}$ & $\mathrm{x}$ & $\mathrm{x}$ & $\mathrm{x}$ & $\mathrm{X}$ & $\mathrm{X}$ \\
\hline & & women & $\mathrm{X}$ & $\mathrm{X}$ & $\mathrm{X}$ & $\mathrm{x}$ & $\mathrm{x}$ & $\mathrm{X}$ & $\mathrm{X}$ & $\mathrm{X}$ \\
\hline \multirow[t]{2}{*}{2008} & Ljubljana & men & $\mathrm{X}$ & $\mathrm{X}$ & $\mathrm{x}$ & $\mathrm{x}$ & $\mathrm{x}$ & $\mathrm{x}$ & $\mathrm{x}$ & $\mathrm{X}$ \\
\hline & & women & $\mathrm{X}$ & $\mathrm{X}$ & $\mathrm{x}$ & $\mathrm{x}$ & $\mathrm{x}$ & $\mathrm{x}$ & $\mathrm{X}$ & $\mathrm{x}$ \\
\hline \multirow[t]{2}{*}{2010} & Nyiregyháza & men & $\mathrm{X}$ & $\mathrm{X}$ & $\mathrm{x}$ & $\mathrm{x}$ & $\mathrm{x}$ & $\mathrm{x}$ & $\mathrm{X}$ & $\mathrm{X}$ \\
\hline & & women & $\mathrm{X}$ & $\mathrm{X}$ & $\mathrm{X}$ & $\mathrm{x}$ & $\mathrm{x}$ & $\mathrm{x}$ & $\mathrm{X}$ & $\mathrm{X}$ \\
\hline \multirow[t]{2}{*}{2012} & Zittau & men & $\mathrm{X}$ & $\mathrm{X}$ & $\mathrm{x}$ & $\mathrm{x}$ & $\mathrm{x}$ & $\mathrm{x}$ & $\mathrm{X}$ & $\mathrm{X}$ \\
\hline & & women & $\mathrm{X}$ & $\mathrm{X}$ & $\mathrm{X}$ & $\mathrm{X}$ & $\mathrm{x}$ & $\mathrm{x}$ & $\mathrm{X}$ & $\mathrm{X}$ \\
\hline \multirow[t]{2}{*}{2014} & Izmir & men & $\mathrm{X}$ & $\mathrm{X}$ & $\mathrm{X}$ & $\mathrm{X}$ & $\mathrm{X}$ & $\mathrm{X}$ & $\mathrm{X}$ & $\mathrm{X}$ \\
\hline & & women & $\mathrm{x}$ & $\mathrm{X}$ & $\mathrm{x}$ & $\mathrm{X}$ & $\mathrm{X}$ & $\mathrm{x}$ & $\mathrm{X}$ & $\mathrm{X}$ \\
\hline
\end{tabular}


Table 2 Coefficients (C) and standard errors of estimate (SEE) from multi-variate regression models for race speed of participants by sex and race distance.

609

\begin{tabular}{lccc}
\hline & C & SEE & p \\
\hline Sex & -3.18 & 0.08 & $<0.001$ \\
Race distance & -2.06 & 0.02 & $<0.001$ \\
Interaction sex $\times$ race distance & 0.17 & 0.02 & $<0.001$ \\
\hline
\end{tabular}

610

611 
612 Table 3 Coefficients (C) and standard errors of estimate (SEE) from multi-variate 613 regression models for race speed of participants by sex and age group for each race 614 distance.

615

616

\begin{tabular}{|c|c|c|c|c|}
\hline & & C & SEE & $\mathbf{p}$ \\
\hline \multirow{3}{*}{$100 \mathrm{~m}$} & Sex & -4.06 & 0.18 & $<0.001$ \\
\hline & Age group & -1.19 & 0.02 & $<0.001$ \\
\hline & Interaction sex $\times$ age group & -0.10 & 0.03 & 0.001 \\
\hline \multirow{3}{*}{$200 \mathrm{~m}$} & Sex & -4.63 & 0.17 & $<0.001$ \\
\hline & Age group & -1.29 & 0.02 & $<0.001$ \\
\hline & Interaction sex $\times$ age group & -0.02 & 0.03 & 0.481 \\
\hline \multirow{3}{*}{$400 \mathrm{~m}$} & Sex & -5.21 & 0.15 & $<0.001$ \\
\hline & Age group & -1.34 & 0.02 & $<0.001$ \\
\hline & Interaction sex $\times$ age group & 0.14 & 0.03 & $<0.001$ \\
\hline \multirow{3}{*}{$800 \mathrm{~m}$} & Sex & -4.85 & 0.13 & $<0.001$ \\
\hline & Age group & -1.24 & 0.01 & $<0.001$ \\
\hline & Interaction sex $\times$ age group & 0.23 & 0.03 & $<0.001$ \\
\hline \multirow{3}{*}{$1500 \mathrm{~m}$} & Sex & -4.37 & 0.14 & $<0.001$ \\
\hline & Age group & -1.08 & 0.02 & $<0.001$ \\
\hline & Interaction sex $\times$ age group & 0.20 & 0.03 & $<0.001$ \\
\hline \multirow{3}{*}{$5000 \mathrm{~m}$} & Sex & -4.16 & 0.11 & $<0.001$ \\
\hline & Age group & -0.98 & 0.01 & $<0.001$ \\
\hline & Interaction sex $\times$ age group & 0.21 & 0.02 & $<0.001$ \\
\hline \multirow{3}{*}{$1000 \mathrm{~m}$} & Sex & -4.13 & 0.15 & $<0.001$ \\
\hline & Age group & -0.91 & 0.02 & $<0.001$ \\
\hline & Interaction sex $\times$ age group & 0.27 & 0.03 & $<0.001$ \\
\hline \multirow{3}{*}{ Marathon } & Sex & -4.51 & 0.18 & $<0.001$ \\
\hline & Age group & -0.82 & 0.02 & $<0.001$ \\
\hline & Interaction sex $\times$ age group & 0.35 & 0.04 & $<0.001$ \\
\hline
\end{tabular}

617 
618 Table 4 Coefficients (C) and standard errors of estimate (SEE) from multi-variate 619 regression models for race speed of participants by sex and calendar year for each 620 race distance.

621

\begin{tabular}{|c|c|c|c|c|}
\hline & & $\mathbf{C}$ & SEE & $\mathbf{p}$ \\
\hline \multirow{3}{*}{$100 \mathrm{~m}$} & Sex & -0.87 & 33.20 & 0.979 \\
\hline & Calendar year & 0 & 0.01 & 0.948 \\
\hline & Interaction sex $\times$ calendar year & 0 & 0.02 & 0.944 \\
\hline \multirow{3}{*}{$200 \mathrm{~m}$} & Sex & -58.47 & 35.01 & 0.095 \\
\hline & Calendar year & -0.02 & 0.01 & 0.161 \\
\hline & Interaction sex $\times$ calendar year & 0.03 & 0.02 & 0.113 \\
\hline \multirow{3}{*}{$400 \mathrm{~m}$} & Sex & 6.67 & 34.19 & 0.845 \\
\hline & Calendar year & -0.01 & 0.01 & 0.636 \\
\hline & Interaction sex $\times$ calendar year & 0 & 0.02 & 0.783 \\
\hline \multirow{3}{*}{$800 \mathrm{~m}$} & Sex & 25.81 & 29.66 & 0.384 \\
\hline & Calendar year & -0.01 & 0.01 & 0.219 \\
\hline & Interaction sex $\times$ calendar year & -0.01 & 0.01 & 0.348 \\
\hline \multirow{3}{*}{$1500 \mathrm{~m}$} & Sex & 4.77 & 24.40 & 0.845 \\
\hline & Calendar year & -0.02 & 0.01 & 0.003 \\
\hline & Interaction sexxcalendar year & 0 & 0.01 & 0.779 \\
\hline \multirow{3}{*}{$5000 \mathrm{~m}$} & Sex & -13.03 & 20.69 & 0.529 \\
\hline & Calendar year & -0.02 & 0.01 & 0.010 \\
\hline & Interaction sex $\times$ calendar & 0.01 & 0.01 & 0.596 \\
\hline \multirow{3}{*}{$1000 \mathrm{~m}$} & Sex & 39.86 & 35.34 & 0.260 \\
\hline & Calendar year & -0.02 & 0.01 & 0.017 \\
\hline & Interaction sexxcalendar year & -0.02 & 0.02 & 0.239 \\
\hline \multirow{3}{*}{ Marathon } & Sex & -3.69 & 22.42 & 0.869 \\
\hline & Calendar year & -0.02 & 0.01 & 0.002 \\
\hline & Interaction sexxcalendar year & 0 & 0.01 & 0.946 \\
\hline
\end{tabular}




\section{List of figures}

625

626 Figure 1 Speed by race distance and sex. Women are depicted by $\boldsymbol{\Delta}$ and men by

$\bullet$.

628

629

630

Figure 2 Relationship between speed and race duration for women and men. Women are depicted by $\boldsymbol{\Delta}$ and men by $\bullet$.

631

632

633

Figure 3 Speed by age group and sex for each race distance. Women are depicted by $\boldsymbol{\Lambda}$ and men by $\bullet$.

634

635

636

Figure 4 Speed by calendar year and sex for each race distance. Women are depicted by $\boldsymbol{\Lambda}$ and men by $\bullet$.

637

638 Figure 5 Sex difference in speed by race distance and calendar year. 
640

Figure 1

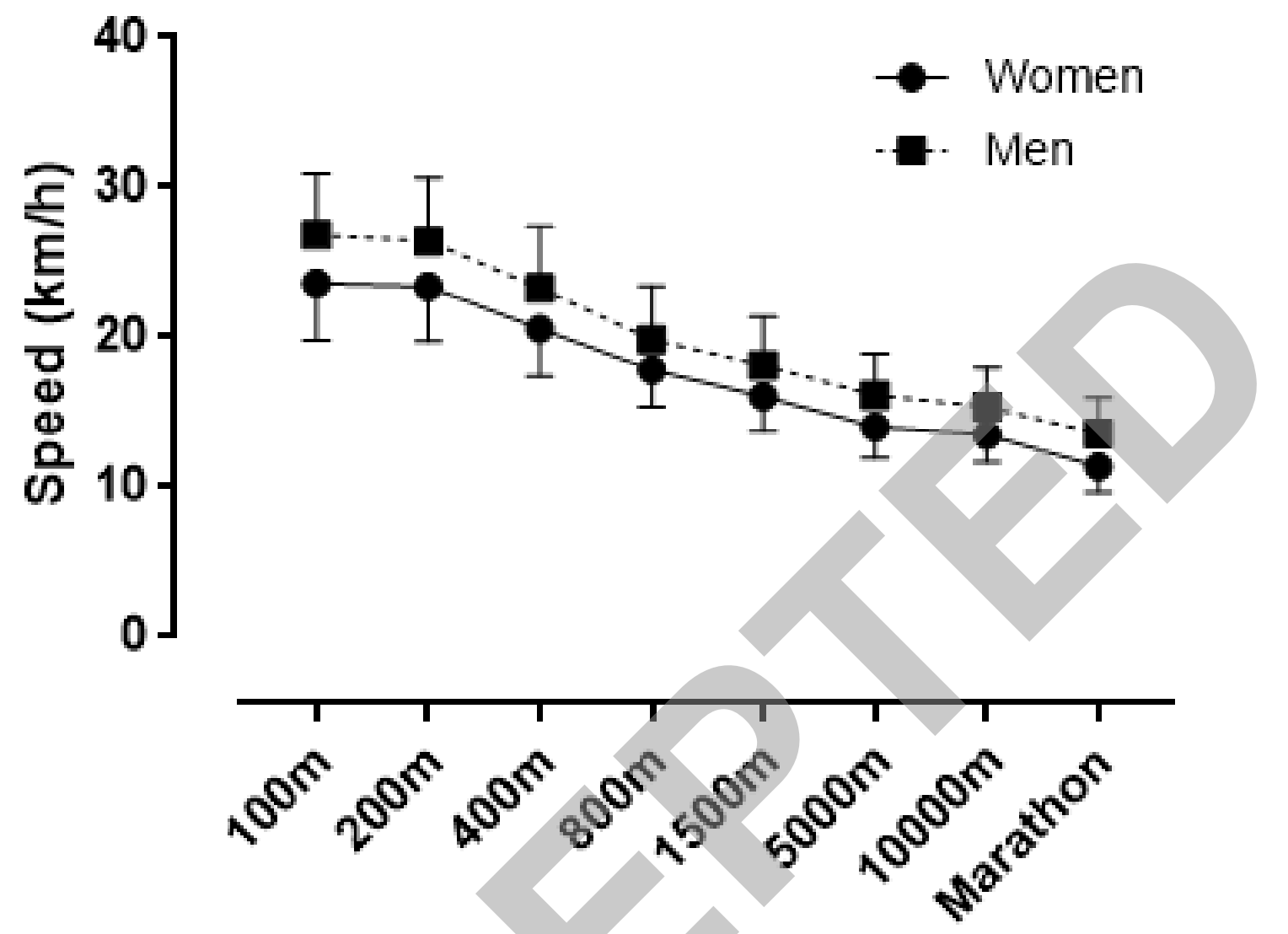

641

Race distance

642 
Figure 2

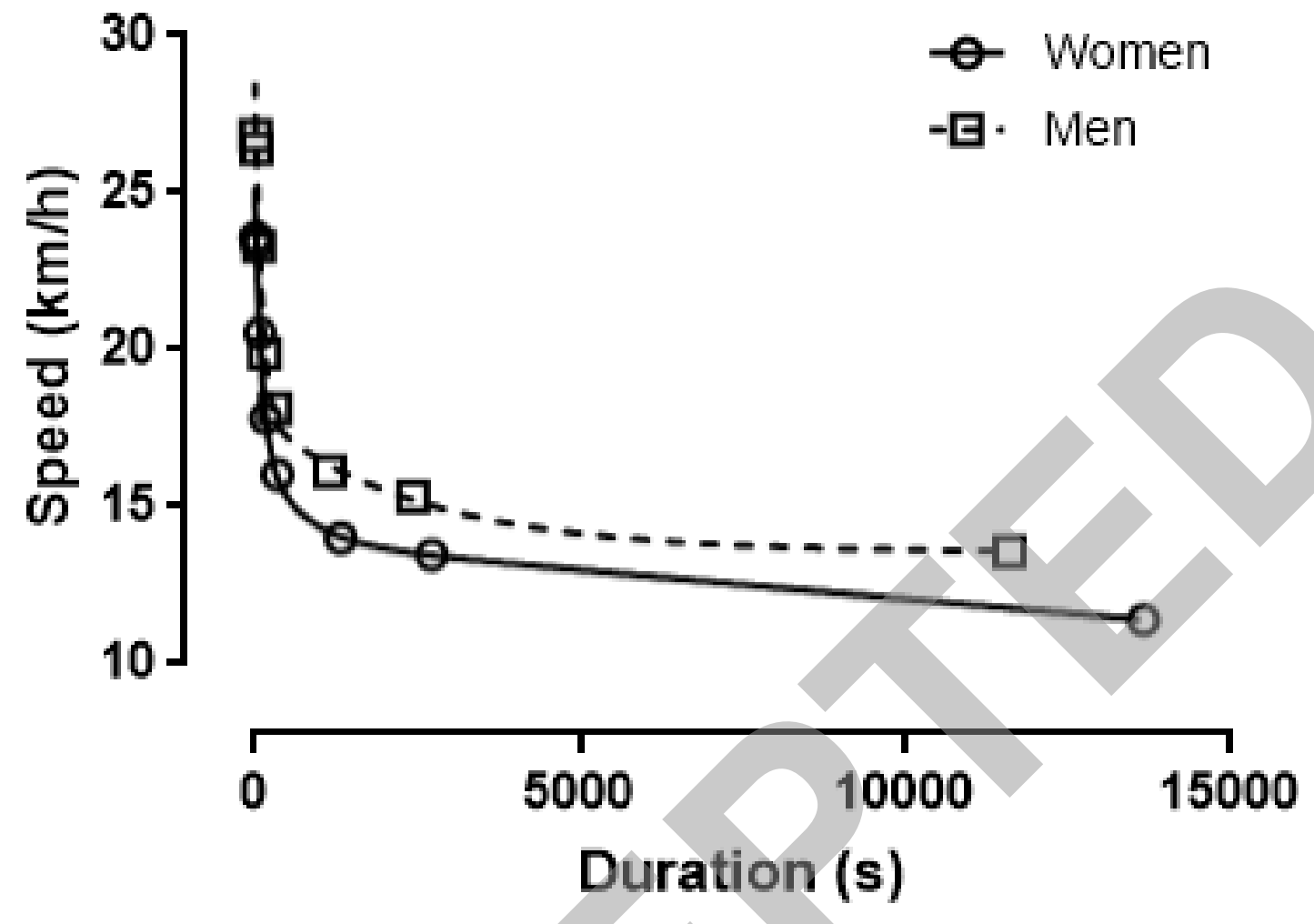

645 
Figure 3
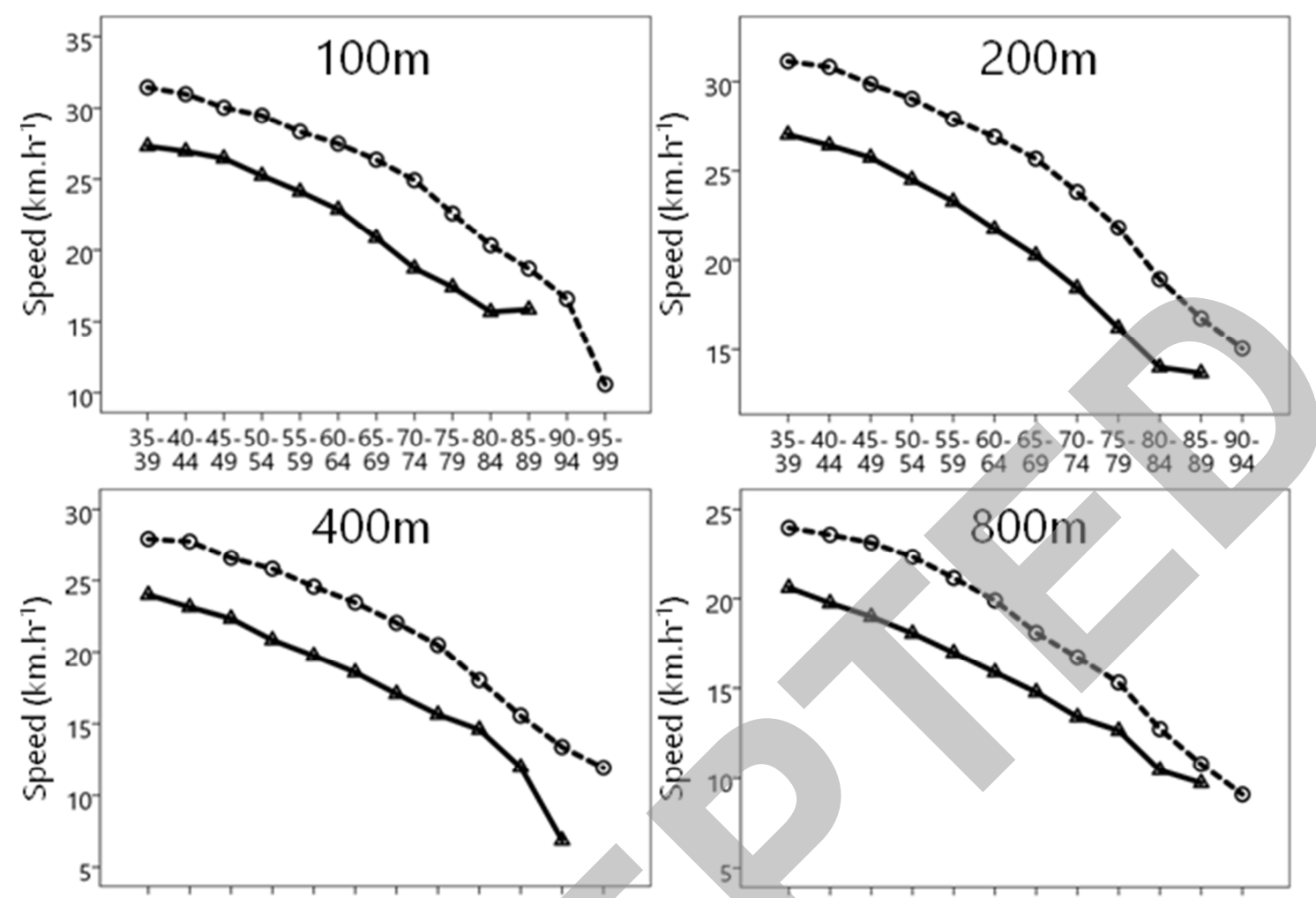

$35-40-45-50-55-60-65-70-75-80-85-90-$
$3944 \quad 49 \quad 54 \quad 5964 \quad 6974 \quad 79 \quad 84 \quad 89 \quad 94$

$35-40$ - 45 - 50 - 55 - 60 - 65 - 70- 75 - 80 - 85 - 90 -

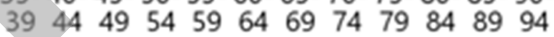

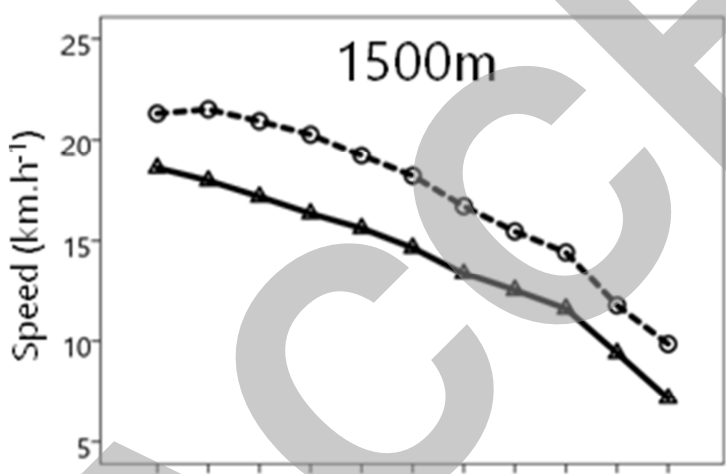

35- $40-45-50-55-60-65-70-75-80-85$.

$\begin{array}{lllllllllll}39 & 44 & 49 & 54 & 59 & 64 & 69 & 74 & 79 & 84 & 89\end{array}$

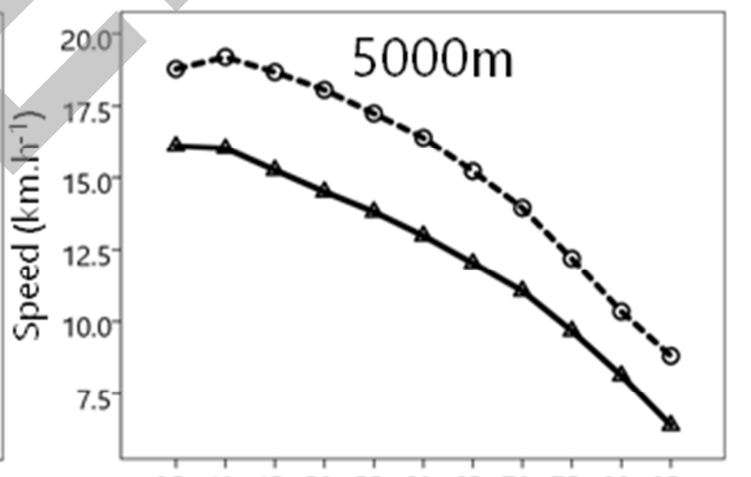

35- 40 - 45 - 50- 55- 60 - 65 - 70- 75 - 80 - 85 $\begin{array}{lllllllllll}39 & 44 & 49 & 54 & 59 & 64 & 69 & 74 & 79 & 84 & 89\end{array}$

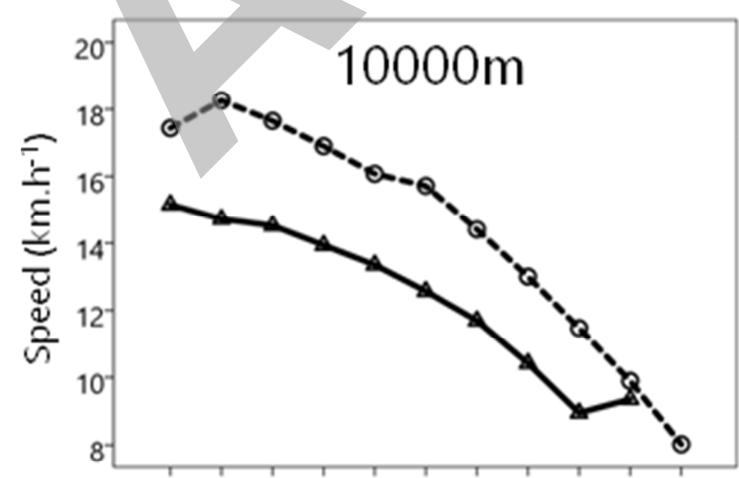

35- 40 - 45 - 50- 55- 60 - 65 - 70- $75-80$ - 85 $\begin{array}{lllllllllll}39 & 44 & 49 & 54 & 59 & 64 & 69 & 74 & 79 & 84 & 89\end{array}$ Age groups

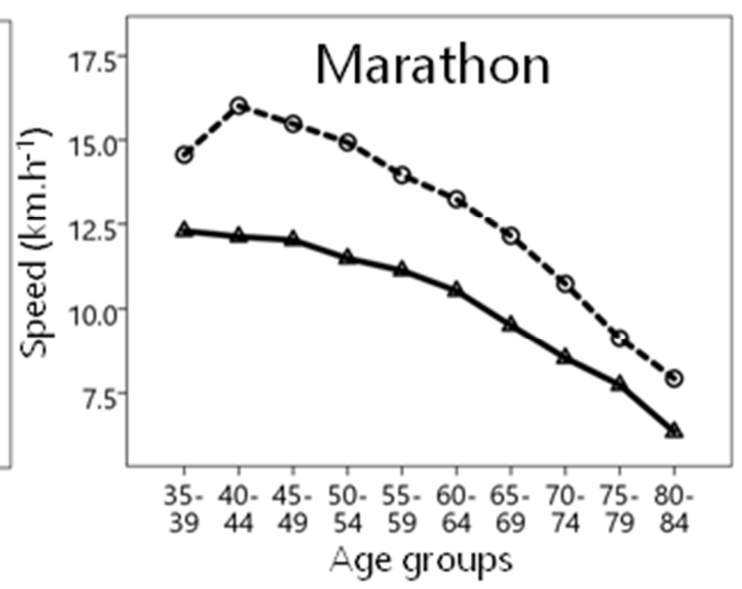


Figure 4
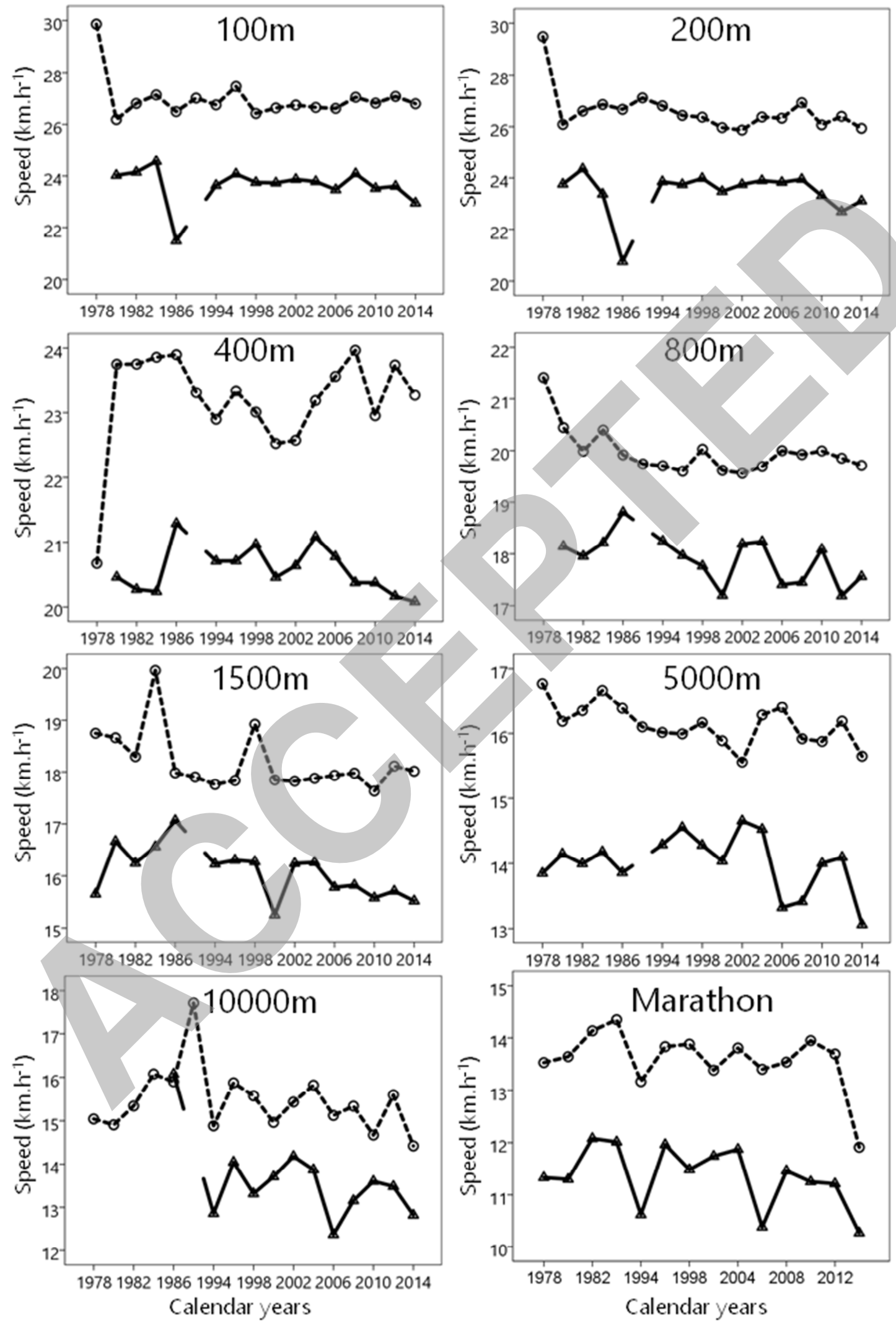
$651 \quad$ Figure 5

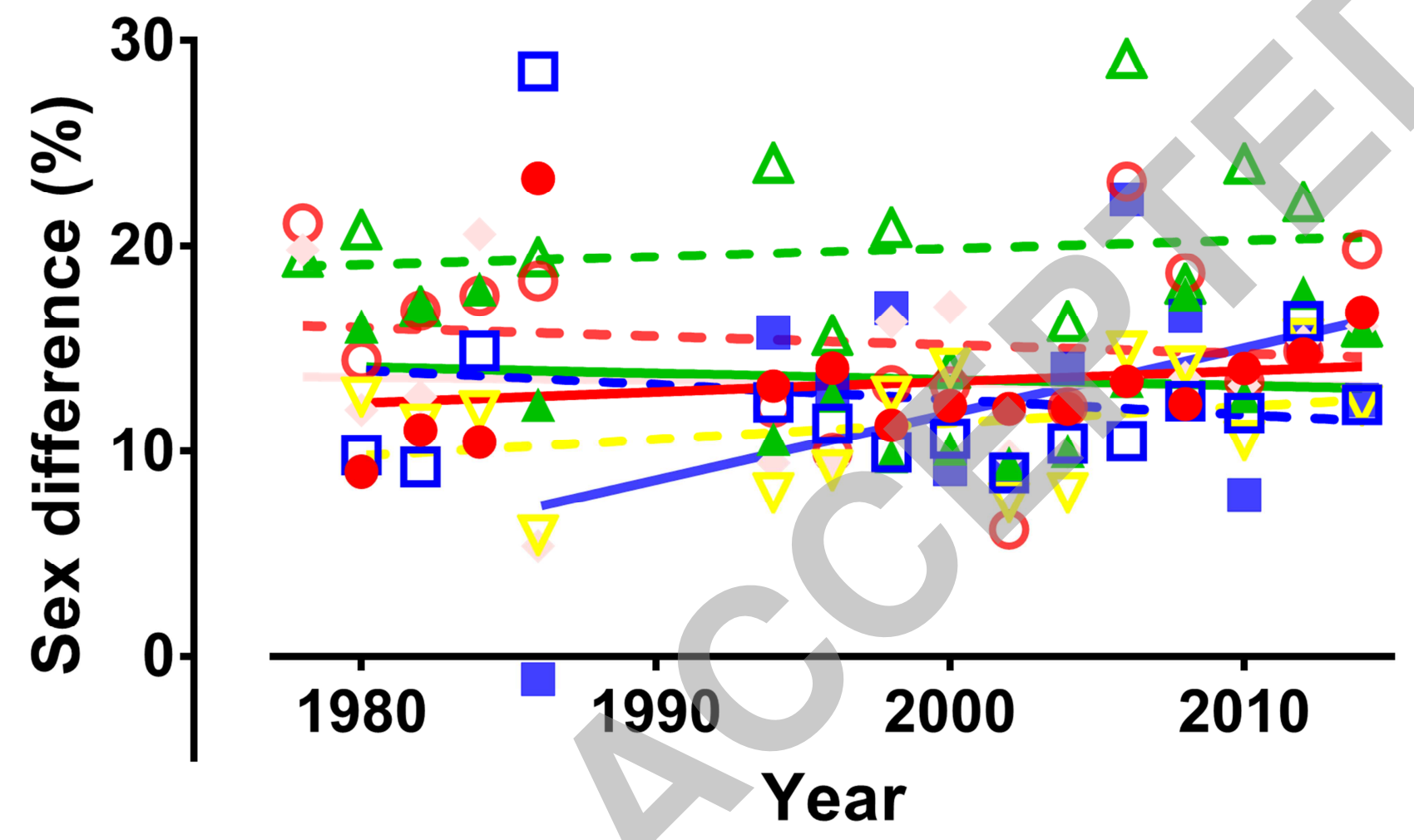

- $100 \mathrm{~m}$

๑200m

$+400 \mathrm{~m}$

7. $800 \mathrm{~m}$

$-1500 \mathrm{~m}$

- $5000 \mathrm{~m}$

- $10000 \mathrm{~m}$

$\triangle$ Marathon 